\title{
PRODUÇÃO E CONSUMO DE CARBONO ORGÂNICO NA COMUNIDADE PLANCTÔNICA DA REPRESA DA PAMPULHA, MINAS GERAIS, BRASIL
}

\author{
MARCOS A. R. ARAÚJO e RICARDO M. PINTO-COELHO \\ Departamento de Biologia Geral, ICB, Universidade Federal de Minas Gerais, Av. Antônio Carlos, 6627, C.P. 486, \\ CEP 30161-970, Belo Horizonte, MG, Brasil \\ Correspondência para: Ricardo Motta Pinto-Coelho, Laboratório de Ecofisiologia de Organismos Planctônicos, Departamento de \\ Biologia Geral, ICB, Universidade Federal de Minas Gerais, C.P. 486, CEP 30161-970, Belo Horizonte, MG, Brasil \\ Recebido em 01/04/97 - Aceito em 27/05/98 - Distribuído em 28/08/98
}

(Com 5 figuras)

\section{ABSTRACT \\ Carbon production and consumption of the planktonic community from Pampulha Reservoir, Minas Gerais State, Brazil}

The basic aim of the present investigation was related to the question: How important is the phytoplankton as a food resource for zooplankton in a tropical hypereutrophic reservoir? For answering this question, two different approaches were adopted. The first one included a regular monitoring program aimed to follow the composition and biomass of zooplankton as well as the major food resources, expressed in terms of C-biomass of sestonic particles. A second approach included the experimental determination of the balance between production and consumption of organic carbon in the planktonic community of Pampulha Reservoir. This was done through simultaneous determination of maximum potential primary production and assimilation rates of mesozooplankton estimated from respiration rates. The algal production was evaluated considering two different size fractions: a) nanno- $(<50 \mu \mathrm{m})$ and b) net phytoplankton $(50-160 \mu \mathrm{m})$. The respiration of zooplankton community was restricted to larger organisms (mesozooplankton). These rates were determined at the laboratory under optimal conditions of illumination and temperature.

Field data from the monitoring program showed that the limnetic zone of the reservoir supported a relatively low algal biomass for most parts of the seasonal cycle $\left(<30 \mu \mathrm{g} \cdot \mathrm{L}^{-1}\right)$. Except the short term algal (Microcystis spp.) blooming periods, chlorophyll-a concentrations in the water column remained at relatively low levels. The annual range of chlorophyll-a was 0-126 $\mu \mathrm{g} . \mathrm{L}^{-1}$. Furthermore, field data also indicated that the bulk of the sestonic carbon was concentrated on non-pigmented particles.

Evidences from laboratory suggested that the carbon demand of zooplankton could not be supplied by primary producers from the limnetic zone alone. The potential primary production ranged from low to moderate values (2.0-37.3 mgC. $\left.\mathrm{m}^{-3} \mathrm{~h}^{-1}\right)$ and, as a consequence, assimilation rates of zooplankton remained higher than algal production $(<50 \mu \mathrm{m})$ for most parts of the year. Considering these evidences from field and laboratory, this study concludes that the energetic demand of (meso)zooplankton was, to a large extent, supplied by the detrital food chain.

Key words: primary production, secondary production, particulate organic carbon, zooplankton.

\section{RESUMO}

O presente estudo tem por objetivo investigar a importância relativa do fitoplâncton como recurso alimentar para o zooplâncton em um reservatório hipereutrófico tropical. Para atingir esta meta, dois enfoques foram adotados. O primeiro deles consistiu num monitoramento regular (mensal) dos teores de biomassa do zooplâncton e das suas fontes de alimento expressas em termos de biomassa de carbono de partículas sestônicas. O segundo enfoque consistiu numa abordagem experimental com o objetivo 
de determinar o balanço entre a produção primária e o consumo de carbono orgânico na comunidade planctônica do reservatório. Tal avaliação deu-se através da mensuração simultânea das taxas de produção primária líquida potencial do fitoplâncton e das taxas de assimilação da comunidade mesozooplanctônica, derivadas a partir das taxas de respiração. A produção primária foi estimada em duas frações distintas: a) $50-160 \mu \mathrm{m} \mathrm{e} \mathrm{b)}<50 \mu \mathrm{m}$. Tanto a produção primária quanto a respiração do zooplâncton foram estimadas simultaneamente no laboratório sob condições controladas de iluminação e temperatura.

O programa de monitoramento indicou que, excetuando breves períodos nos quais ocorreu o florescimento de Cyanobacteria coloniais (Microcystis spp.), a biomassa da comunidade fitoplanctônica foi quase sempre reduzida na zona limnética do reservatório $\left(<30 \mu \mathrm{g} . \mathrm{L}^{-1}\right)$. A faixa de oscilação da clorofila-a restringiu-se a 0-126 $\mu \mathrm{g} . \mathrm{L}^{-1}$. Adicionalmente, a maior parte do carbono particulado foi de origem não pigmentada.

Os estudos experimentais indicaram que a demanda energética do zooplâncton, em termos de carbono, não pode ser suprida pela produção devida ao fitoplâncton no Reservatório da Pampulha. A produção primária potencial oscilou entre 2,0 e $37,3 \mathrm{mgC} \cdot \mathrm{m}^{-3} \cdot \mathrm{h}^{-1}$, valores estes que ficaram muito abaixo das taxas de assimilação devidas ao zooplâncton em diferentes épocas do ano.

Considerando as evidências obtidas no campo e aquelas provenientes dos estudos experimentais, o presente estudo conclui que a demanda de carbono do mesozooplâncton durante o período de estudos foi em grande parte coberta através da cadeia de detritos.

Palavras-chave: produção primária, produção secundária, carbono orgânico particulado, zooplâncton.

\section{INTRODUÇÃO}

Dentro de uma visão clássica da Ecologia, o fitoplâncton é tido como a base do fluxo de carbono das cadeias tróficas na região limnética de ambientes aquáticos (Pomeroy, 1974; Fenchel, 1988). No entanto, estudos realizados nas últimas décadas mostraram que isto nem sempre é verdade. Os detritos, as bactérias e protozoários podem, em alguns casos, ser mais importantes do que os produtores primários como fonte de carbono para os níveis tróficos superiores (Azam et al., 1983). As bactérias eram vistas anteriormente apenas como responsáveis pela decomposição da matéria orgânica e pela ciclagem dos nutrientes.

Com o desenvolvimento de novas técnicas para o estudo da ecologia microbiana, tais como a citometria de fluxo, a microscopia de epifluorescência (Weisse, 1994), os microheterótrofos planctônicos foram reconhecidos como importantes componentes no fluxo de carbono em muitas cadeias tróficas aquáticas, através do que se convencionou chamar "microbial loop" (Stockner \& Porter, 1988; Pomeroy \& Wiebe, 1988; Weisse, 1990).

O carbono é um dos constituintes essenciais da biomassa dos seres vivos, sendo responsável por $40 \%$ a $60 \%$ do peso seco, na maioria dos casos (Raymont, 1983). Devido a esta importância, ele é usado como unidade universal em ecologia energética, permitindo comparar a dinâmica de ecossistemas muito diferentes entre si.

De modo geral, os estudos limnológicos realizados nas regiões tropicais são muito fragmentados, não fornecendo uma visão global de como se dá o fluxo de carbono nestes sistemas.

Alguns estudos enfocam apenas a composição, abundância ou a produção primária do fitoplâncton, enquanto outros enfocam apenas a composição e abundância dos organismos zooplanctônicos (Schmidt, 1973; Talling et al., 1973; Arcifa, 1984; Sendacz, 1984; Gianesella-Galvão, 1985; Erikson et al., 1991; Cisseros \& Mangas, 1991). Estudos integrando produção primária e produção secundária são muito escassos nestas regiões.

O objetivo do presente trabalho foi avaliar qual é o papel do fitoplâncton como recurso alimentar para o zooplâncton em um reservatório hipereutrófico tropical. Esta avaliação foi feita através da comparação entre as principais fontes de carbono orgânico para a comunidade mesozooplanctônica a partir de um programa regular de monitoramento no reservatório. Um segundo enfoque consistiu numa abordagem experimental em que as taxas de produção primária e as taxas de assimilação do zooplâncton foram medidas no la- 
boratório sob condições controladas de temperatura e iluminação.

\section{ÁREA DE ESTUDOS}

A represa estudada situa-se no perímetro urbano de Belo Horizonte, MG (4356'47' W e $19^{\circ} 55^{\prime} 09^{\prime \prime}$ ). Ela foi inaugurada em 1938 e reconstruída em 1957. O conjunto arquitetônico construído à sua volta constitui-se em importante área de turismo e lazer da cidade. Na época de sua construção, continha cerca de 18 milhões de $\mathrm{m}^{3}$ de água, área de 260 hectares, profundidade média de $5 \mathrm{~m}$ e profundidade máxima de $16 \mathrm{~m}$ (Champs, 1991).

A ocupação desordenada de sua bacia de drenagem trouxe grande degradação ambiental para este corpo d'água, representada na forma de um adiantado processo de eutrofização e assoreamento. Durante a década de 80 , houve um agravamento do processo de eutrofização (Giani et al., 1988). Devido ao intenso processo de assoreamento a que está submetida a represa da
Pampulha, calcula-se que restem atualmente apenas 11 milhões de $\mathrm{m}^{3}$ de água e que o aporte anual de sedimentos é superior a $380.000 \mathrm{~m}^{3}$. Se mantidas as tendências atuais, em 20 anos a represa deixará de existir (Champs, 1992).

A estação de coletas estava localizada próxima à região central da represa, tendo uma profundidade máxima de cerca de $7 \mathrm{~m}$ (Fig. 1).

\section{METODOLOGIA}

O balanço de carbono orgânico na represa da Pampulha, ou seja, a relação entre produção e consumo, foi determinado indiretamente através da comparação entre a taxa de produção primária líquida potencial do fitoplâncton $(<50 \mu \mathrm{m})$ e a taxa de assimilação do zooplâncton.

\section{Produção primária potencial do fitoplâncton}

A produção primária potencial do fitoplâncton $<50 \mu \mathrm{m}$ foi medida em laboratório nos meses de fevereiro, abril, agosto, setembro e novembro de 1994. A metodologia usada foi a da

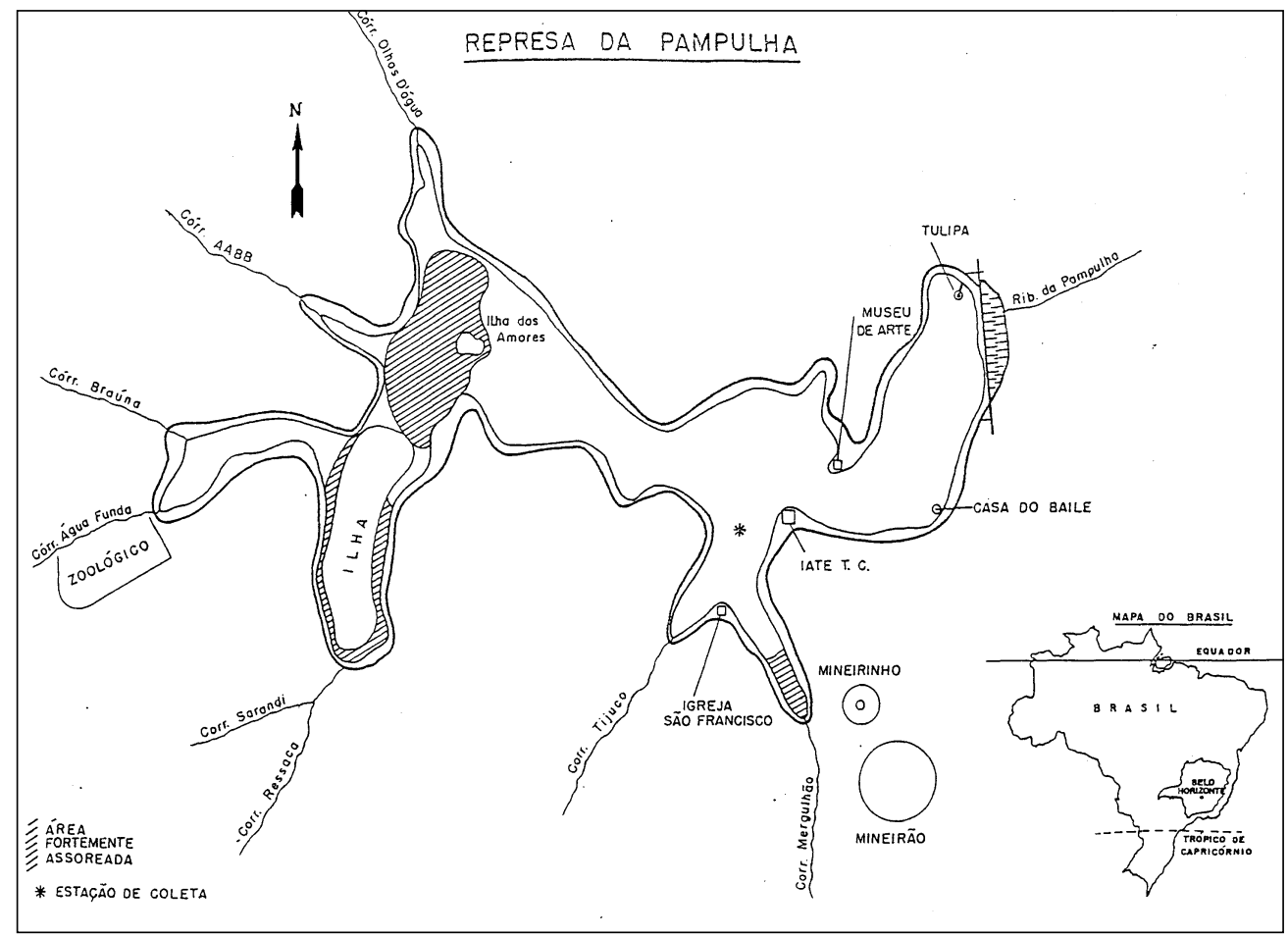

Fig. 1 - Mapa da Represa da Pampulha, situada no município de Belo Horizonte, Minas Gerais, mostrando a estação de coleta. 
determinação da concentração do oxigênio dissolvido em frascos claros e escuros (Vollenweider, 1974). Foram coletados 5 litros de água à profundidade de Secchi, com garrafa de Kemmerer. Escolheu-se a profundidade de Secchi para evitar possível efeito da inibição superficial da fotossíntese. As amostras foram acondicionadas em galões de plástico e transportadas para o laboratório, em no máximo 30 minutos.

No laboratório, 5 litros de água foram transferidos para um aquário de vidro, após filtração em rede de $50 \mu \mathrm{m}$, para a retirada do fitoplâncton e micro-herótrotrofos maiores do que $50 \mu \mathrm{m}$. Deste aquário, foi retirado, cuidadosamente, para não haver borbulhamento, 8 amostras em frascos de vidro de $250 \mathrm{ml}$ (Pyrex no 1500), sendo 3 frascos transparentes, 3 opacos e 2 frascos iniciais, onde se procedeu à imediata determinação do oxigênio dissolvido. O oxigênio dissolvido foi determinado pelo método iodométrico (Winkler, 1888, modificado por Pomeroy \& Kirschmann, 1945). Os frascos transparentes e os opacos foram colocados em estufa incubadora, com temperatura ajustada à do lago no momento da coleta e com aproximadamente 1400 LUX de iluminação através de lâmpadas fluorescentes brancas, por cerca de 4 horas. Após o período de incubação, procedeu-se à determinação do oxigênio dissolvido nos frascos claros e escuros e o posterior cálculo da produção primária de acordo com as equações fornecidas por Vollenweider (1974).

Os valores de produção primária, obtidos em $\mathrm{mgO}_{2} \cdot \mathrm{L}^{-1}$, foram convertidos para $\mathrm{mgC}$. $\mathrm{L}^{-1}$ utilizando-se o quociente fotossintético (QF) igual a 1,2 (Vollenweider, 1974; Williams \& Robertson, 1991). Os valores de produção primária bruta e líquida do fitoplâncton menor do que $50 \mathrm{~mm}$, para os meses situados entre as datas dos experimentos, foram obtidos através de interpolação linear, utilizando-se escala Juliana, em programa Turbo Pascal.

Em seguida, esses valores de produção primária, obtidos em laboratório, foram extrapolados para a realidade de campo, através da equação fornecida por Vollenweider (1974).

$$
P\left(g C \cdot m^{-2} \cdot d i a^{-1}\right)=0,80 \times P P l(l a b) \times \frac{\lambda}{\omega} \times
$$

$$
\ln (1,5 \times 5,44)
$$

em que:

$\mathrm{P}=$ produção primária em $\mathrm{gC} \cdot \mathrm{m}^{-2} \cdot \mathrm{dia}^{-1}$;

$\operatorname{PPl}(\mathrm{lab})=$ produção primária líquida obtida em laboratório em $\mathrm{mgC} \cdot \mathrm{m}^{-3} \cdot \mathrm{h}^{-1}$;

$\lambda=$ comprimento do dia em horas;

$\mathrm{w}=$ coeficiente de extinção da radiação ativa $(=\mathrm{K})$.

\section{Medida da respiração da comunidade mesozoo-} planctônica

A taxa de respiração da comunidade zooplanctônica foi medida nas mesmas datas em que se determinou a produção primária. $\mathrm{O}$ zooplâncton foi coletado na Represa da Pampulha, por meio de arrastos verticais $(3 \mathrm{~m})$ com rede de 90 $\mu \mathrm{m}$, acondicionado em garrafa térmica e rapidamente transportado para o laboratório. No laboratório, o zooplâncton foi transferido, após filtragem em rede de $160 \mu \mathrm{m}$, para aquário de vidro contendo $10 \mathrm{~L}$ de água da represa. Deste aquário, foram retirados 4 frascos de vidro de $500 \mathrm{ml}$ contendo entre 10-150 mgPS de zooplâncton e 4 frascos de mesmo volume sem zooplâncton. Todos os frascos foram incubados em estufa germinadora com temperatura ajustada à do lago. Após o período de incubação, foi retirado de cada frasco uma alíquota de $250 \mathrm{ml}$ para determinação do oxigênio dissolvido na água.

A biomassa foi determinada através de pesagem em balança Mettler modelo H64, após prévia liofilização. As redes contendo zooplâncton foram congeladas a $-18^{\circ} \mathrm{C}$ e liofilizadas por 24 horas em um liofilizador Edwards L5KR a 0,6-0,8 x $10^{-2}$ mbar de pressão, segundo a técnica descrita por Berberovic \& Pinto-Coelho (1989). Depois de retirado do liofilizador, o zooplâncton foi pesado, após ter permanecido 24 horas em dissecador contendo sílica gel, para retirada da umidade restante. A respiração da comunidade zooplanctônica foi calculada com a equação abaixo:

$$
\mathrm{R}\left(\mathrm{mgO}_{2} \cdot \mathrm{L}^{-1} \cdot \mathrm{h}^{-1}\right)=\frac{\mathrm{C}-\mathrm{Z}}{\mathrm{Ti}}
$$

em que:

$\mathrm{R}=$ respiração;

$\mathrm{C}=$ oxigênio dissolvido na água do frasco controle;

$\mathrm{Z}=$ oxigênio dissolvido na água do frasco contendo zooplâncton;

$\mathrm{Ti}$ = tempo de incubação (h). 
A taxa de respiração peso-específica (TR) da comunidade mesozooplanctônica foi calculada dividindo-se o valor da respiração pela biomassa de zooplâncton presente em cada frasco, segundo a equação abaixo:

$\operatorname{TR}\left(\mathrm{mgO}_{2} \cdot \mathrm{mgPS}^{-1} \cdot \mathrm{h}^{-1}\right)=\frac{\mathrm{R}\left(\mathrm{mgO}_{2} \cdot \mathrm{L}^{-1} \cdot \mathrm{h}^{-1}\right)}{\mathrm{B}\left(\mathrm{mgPS} \cdot \mathrm{L}^{-1}\right)}$

em que:

TR = taxa de respiração da comunidade mesozooplanctônica;

$\mathrm{R}=$ respiração;

$\mathrm{B}=$ biomassa.

Os valores de $\mathrm{TR}$ em $\mathrm{mgO}_{2} \cdot \mathrm{mgPS}^{-1} \cdot \mathrm{h}^{-1}$ foram convertidos em mgC.mgPS ${ }^{-1} \cdot h^{-1}$ utilizando-se o coeficiente respiratório de 1,03 segundo Lampert (1984). Os valores de TR, obtidos em cada experimento, foram extrapolados para os meses subseqüentes a cada experimento, através de interpolação não-linear (algoritmo de Bezier) em programa Turbo Pascal versão 5.1.

Determinação da produção secundária da comunidade mesozooplanctônica a partir da taxa de respiração

O método fisiológico de Winberg, descrito por Pourriot \& Champ (1982), propõe que a produção secundária pode ser estimada a partir da TR desde que o rendimento líquido $\mathrm{K}_{2}$ (produção/ assimilação) seja conhecido. $\mathrm{O} \mathrm{K}_{2}$ representa a fração da assimilação que é utilizada na produção secundária. A produção foi obtida de acordo com a equação:

$$
\mathrm{P}\left(\mathrm{mgC} \cdot \mathrm{mgPS} \cdot \mathrm{h}^{-1}\right)=\mathrm{TR} \times \frac{\mathrm{K}_{2}}{1-\mathrm{K}_{2}}
$$

em que:

$\mathrm{TR}=$ taxa de respiração da comunidade mesozooplanctônica;

$\mathrm{K}_{2}=$ constante que varia de acordo com o grupo de organismo considerado.

Os valores de $\mathrm{K}_{2}$ fornecidos por Pourriot \& Champ (1982) são de 0.35 para cladóceros e 0,20 para copépodos. Os valores de $\mathrm{K}_{2}$, utilizados nos cálculos da produção secundária do zooplâncton, foram ponderados de acordo com a composição do zooplâncton (percentual da biomassa total devida a cladóceros e a copépodos) presentes na época do experimento.

A biomassa e a composição do mesozooplâncton foi obtida no banco de dados limnológicos do Laboratório de Ecofisiologia de Organismos Planctônicos do ICB/UFMG.

A partir do valor de produção secundária do mesozooplâncton $\left(\mathrm{mgC} \cdot \mathrm{mgPS}^{-1} \cdot \mathrm{h}^{-1}\right)$, obtido em laboratório, foi possível calcular as variáveis respiração, produção secundária e assimilação diária (mgC.m ${ }^{-2}$.dia) do mesozooplâncton da Represa da Pampulha de acordo com as equações abaixo:

$$
\begin{aligned}
& \text { Resp. }\left(\mathrm{mgC} \cdot \mathrm{m}^{-2} \cdot \text { dia }^{-1}\right)= \\
& \frac{\left(\mathrm{TR}\left(\mathrm{mgC} \cdot \mathrm{h}^{-1}\right) \times \text { Biomassa }\left(\mathrm{mgPS} \cdot \mathrm{m}^{-2}\right)\right.}{\mathrm{mgPS}} \times 24
\end{aligned}
$$

Prod.sec. $\left(\mathrm{mgC} \cdot \mathrm{m}^{-2} \cdot \operatorname{dia}^{-1}\right)=$

$$
\frac{\left(\mathrm{TR}\left(\mathrm{mgC}^{-1} \mathrm{~h}^{-1}\right) \times \text { Biomassa } \text { mgPS. } \mathrm{m}^{-2}\right)}{\mathrm{mgPS}} \times 24
$$

Ass. $\left(\mathrm{mgC} \cdot \mathrm{m}^{-2} \cdot \mathrm{dia}^{-1}\right)=$

Resp. $\left(\mathrm{mgC} \cdot \mathrm{m}^{-2} \cdot\right.$ dia $\left.^{-1}\right)+$ Prod. sec. $\left(\mathrm{mgC} \cdot \mathrm{m}^{-2} \cdot \mathrm{dia}^{-1}\right)$

No valor da assimilação, não está o carbono excretado pelo zooplâncton e nem o carbono utilizado na reprodução.

Fontes de carbono orgânico para o zooplâncton

Detritos, bactérias e outros organismos heterotróficos planctônicos foram indiretamente estimados, através da medida do carbono orgânico particulado $<50 \mu \mathrm{m}$ e da clorofila-a. O carbono devido aos heterótrofos planctônicos e aos detritos pode ser estimado através da diferença entre o carbono orgânico total e o carbono devido às algas, estimado a partir dos dados de clorofila (Strikland, 1960):

$$
\mathrm{COP}_{\text {Chla }}=\mathrm{Chla} \times 30
$$

em que:

$\mathrm{COP}_{\text {Chla }}=$ carbono orgânico particulado presente nos planctônicos autotróficos em mg. $\mathrm{L}^{-1}$;

Chla $=$ valor da clorofila em $\mu \mathrm{g} \cdot \mathrm{L}^{-1}$. 
As amostras de água para determinação da clorofila-a e do COP foram coletadas, mensalmente, de janeiro a dezembro de 1994, com garrafa de Kemmerer, nas profundidades de 0, 2, 4 e $6 \mathrm{~m}$. A clorofila-a foi determinada de acordo com Lorenzen (1967). O carbono orgânico particulado foi determinado através da adaptação da metodologia da Demanda Química de Oxigênio (DQO) descrita por APHA (1992). As amostras de água para a determinação do COP foram filtradas em filtro de fibra de vidro contendo uma camada de diatomito, que segundo Simon \& Tilzer (1987) retém 90\% das bactérias. A mensuração do carbono particulado pelo método da DQO foi recentemente comparada com outro método considerado mais preciso, o analisador automático de CHN (Carlo Erba) e os dados obtidos indicam que o método da DQO produz resultados comparáveis aos obtidos com este último método (Torres et al, 1998).

As análises estatísticas (ANOVA) foram realizadas segundo Sokal \& Rohlf (1981) e Snedecor \& Cochran (1989).

\section{RESULTADOS}

\section{Clorofila-a e carbono orgânico particulado $(C O P)<50 \mu m$}

A concentração da clorofila-a, para a fração do fitoplâncton < $50 \mu \mathrm{m}$ no ano de 1994, apresentou ampla variação, com média anual de 17,5 $\pm 3,2 \mu \mathrm{g}$. $\mathrm{L}^{-1}$ ou $103,0 \mathrm{mg} . \mathrm{m}^{-2}$. Os maiores valores para clorofila-a ocorreram no período seco do ano, notadamente nos meses de julho e agosto (Fig. 2), quando foi registrado um intenso "waterbloom" da Cyanobacteria Microcystis spp.

A concentração média de carbono orgânico particulado $<50 \mu \mathrm{m}(\mathrm{COP})$ foi de $2,4 \pm 0,2$ mg. $\mathrm{L}^{-1}$ ou 13,6 $\pm 2,4 \mathrm{gC} \cdot \mathrm{m}^{-2}$, em 1994. Na superfície, a concentração média foi de $3,1 \pm 0,5 \mathrm{mg} . \mathrm{L}^{-1}$, a partir daí apresentando tendência à diminuição com o aumento da profundidade. Os valores de COP variaram entre 0,0 (novembro, $6 \mathrm{~m}$ ) e 6,4 $\mathrm{mg} . \mathrm{L}^{-1}$ (em maio, 1,0 m), sendo que os maiores resultados foram mensurados durante a estação seca do ano, principalmente entre os meses de maio e outubro (Fig. 3).

A distribuição do carbono orgânico particulado $\left(\mathrm{gC} \cdot \mathrm{m}^{-2}\right)$ estimado para as frações: alga $(<$ $50 \mu \mathrm{m})$, detrito e heterotróficos $(<50 \mu \mathrm{m})$ está representada na Fig. 4. Durante todo o ano, a fração do COP representada pelo carbono dos detritos e dos organismos planctônicos heterotróficos foi bem maior que a fração das algas $(<50 \mu \mathrm{m})$. Apenas no mês de julho, a fração "algas" foi ligeiramente maior que a fração "detrito/heterotróficos". Em 1994, a fração "algas < $50 \mu \mathrm{m}$ " representou cerca de $21,8 \pm 4,6 \%$ do COP e a fração "detritos/heterotróficos", cerca de 78,2 $\pm 4,6 \%$.

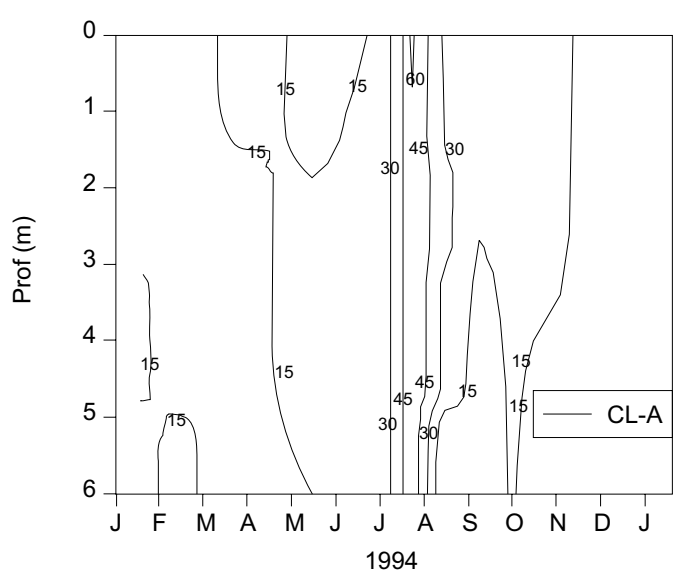

Fig. 2 - Isolinhas de clorofila-a ( $\mu \mathrm{g}$. $\left.\mathrm{L}^{-1}\right)$ na coluna d'água em um ponto central da Represa da Pampulha no ano de 1994. Isolinhas obtidas com o programa SIGMAPLOT para Windows, utilizando interpolação quadrática com aderência máxima (nível 10) aos valores obtidos.

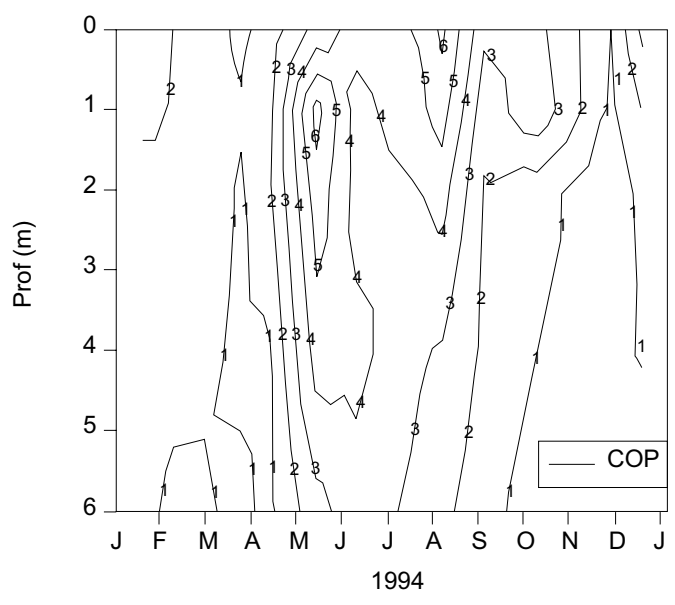

Fig. 3 - Isolinhas de carbono orgânico particulado - COP $\left(\mathrm{mgC} . \mathrm{L}^{-1}\right)$ na coluna d'água em um ponto central da Represa da Pampulha durante o ano de 1994. Isolinhas obtidas com o programa SIGMAPLOT para Windows, utilizando interpolação quadrática com aderência máxima (nível 10) aos valores obtidos (modificado de Torres et al. 1998). 
Produção primária potencial do fitoplâncton

Os experimentos realizados em diferentes épocas do ciclo sazonal, mas sob condições controladas de iluminação e temperatura, indicaram que tanto a PPB como a PPL apresentam os maiores valores no decorrer do período seco do ano, em agosto, e os menores ocorreram no período chuvoso, entre novembro e abril. A PPB variou entre 21,4 (abril) e 95,4 $\mathrm{mgC} \cdot \mathrm{m}^{-3} \cdot \mathrm{h}^{-1}$, registrados em agosto. A PPL oscilou entre 2,0 (abril) e 37,3 $\mathrm{mgC} . \mathrm{m}^{-3} \cdot \mathrm{h}^{-1}$, também mensurados em agosto (Tabela 1).

\section{Respiração do mesozooplâncton}

Os valores de TR variaram de 8,5 a 14,1 $\mu 1 \mathrm{O}_{2} \cdot \mathrm{mg} \cdot \mathrm{PS}^{-1} \cdot \mathrm{h}^{-1}$, com uma média de $11,3 \pm 0,8$ (Tabela 2). Diferenças estatisticamente significativas entre os valores de TR foram encontradas ao longo do ano (ANOVA, $\mathrm{F}=5,6, \mathrm{P}<0,05$ ). $\mathrm{O}$ Teste de Tukey, realizado posteriormente, revelou que os menores valores de TR observados em agosto foram significativamente diferentes dos valores de TR encontrados em janeiro.

Comparação das taxas de produção primária e a assimilação do mesozooplâncton

A assimilação do mesozooplâncton foi maior do que a produção primária líquida da fração $<50 \mu \mathrm{m}$ em todos os experimentos conjuntos realizados (Tabela 3 ). A PPL variou entre 13,45 mgC. $\mathrm{m}^{-2} \cdot \mathrm{d}^{-1}$ (abril) e 206,24 mgC. $\mathrm{m}^{-2} \cdot \mathrm{d}^{-1}$ (agosto). A produção secundária do zooplâncton variou entre 55,31 (novembro) e 160,29 $\mathrm{mgC} . \mathrm{m}^{-2} \cdot \mathrm{d}^{-1}$ (agosto) e a assimilação ficou entre 208,59 (abril) e 485,73 mgC. $\mathrm{m}^{-2} . \mathrm{d}^{-1}$ (agosto).

O desequilíbrio entre a produção e o consumo de carbono na comunidade planctônica do reservatório foi confirmado ao se comparar as estimativas obtidas com as equações (1), (6) e (7). Durante 1994, a assimilação do zooplâncton oscilou entre 71,21 e $656,74 \mathrm{mgC} . \mathrm{m}^{-2} . \mathrm{d}^{-1}$, valores estes que foram superiores aos obtidos para a produção primária, exceto para o mês de janeiro (Fig. 5).

As taxas de assimilação do mesozooplâncton apresentaram dois "picos" principais, um mais elevado em junho e outro um pouco menos intenso em agosto. A produção secundária extrapolada para todo o ano de 1994 apresentou uma faixa de variação igual a 22,81 e $212,53 \mathrm{mgC} \cdot \mathrm{m}^{-2} \cdot \mathrm{d}^{-1}$ (dados não representados). O somatório anual da produção secundária foi de $34,59 \mathrm{gC} . \mathrm{m}^{-2}$, enquanto a assimilação anual chegou a $119,54 \mathrm{gC} . \mathrm{m}^{-2}$. A produção primária líquida anual foi de apenas $37,74 \mathrm{gC}$. $\mathrm{m}^{-2}$.

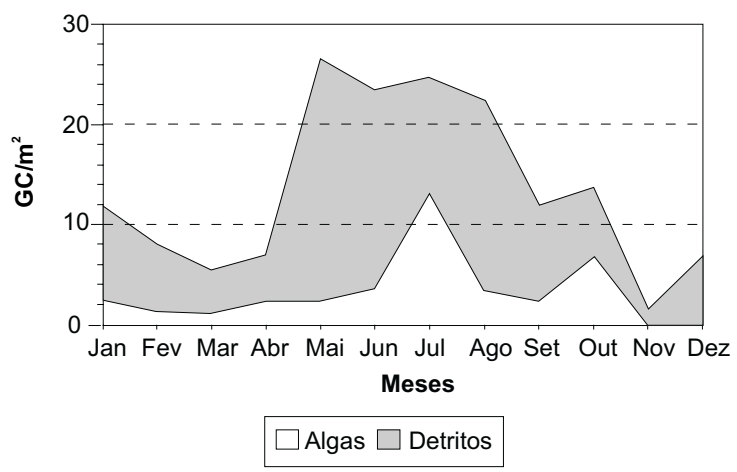

Fig. 4 - Contribuição de diferentes formas de carbono orgânico particulado na Represa da Pampulha durante 1994.

\section{DISCUSSÃO}

Os valores de clorofila-a encontrados para a fração do nanoplâncton $(<50 \mathrm{~mm})$ foram baixos durante o período de estudos, comparando-

TABELA 1

Produções primárias bruta, líquida e respiração, medidas em laboratório, para a fração do fitoplâncton $<50 \mu \mathrm{m}$.

\begin{tabular}{|c|c|c|c|}
\hline Data & $\begin{array}{c}\text { PPB } \\
\text { mgC.m }{ }^{-3} h^{-1}\end{array}$ & $\begin{array}{c}\text { PPL } \\
\operatorname{mgC} \cdot \mathbf{m}^{-3} \cdot \mathbf{h}^{-1}\end{array}$ & $\begin{array}{l}\text { Respiraçãa } \\
\text { mgC.m } \mathbf{m}^{-3} \cdot \mathbf{h}^{-1}\end{array}$ \\
\hline Fevereiro & 27,5 & 16,2 & 11,3 \\
\hline Abril & 21,4 & 2,0 & 19,4 \\
\hline Agosto & 95,4 & 37,3 & 58,1 \\
\hline Setembro & 21,9 & 12,5 & 9,4 \\
\hline Novembro & 17,7 & 8,8 & 8,9 \\
\hline
\end{tabular}


TABELA 2

Taxa de respiração, medida em laboratório, para o mesozooplâncton da Represa da Pampulha: valores médios obtidos a partir de três unidades experimentais.

\begin{tabular}{|c|c|c|c|}
\hline Meses & $\begin{array}{c}\text { TR } \\
\left(\mu 1 \mathrm{O}_{2} \cdot \mathrm{mgPS}^{-1} \cdot \mathbf{h}^{-1}\right)\end{array}$ & $\begin{array}{c}\text { TR } \\
\left(\mathrm{mgO}_{2} \cdot \mathrm{mgPS}^{-1} \cdot \mathbf{h}^{-1}\right)\end{array}$ & 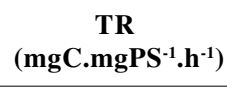 \\
\hline Janeiro & $14,1 \pm 0,68$ & $0,020 \pm 0,001$ & $0,0074 \pm 0,0004$ \\
\hline Abril & $9,3 \pm 0,48$ & $0,013 \pm 0,001$ & $0,0049 \pm 0,0003$ \\
\hline Agosto & $8,5 \pm 0,62$ & $0,012 \pm 0,001$ & $0,0044 \pm 0,00030$ \\
\hline Novembro & $13,2 \pm 2,29$ & $0,019 \pm 0,004$ & $0,0069 \pm 0,001$ \\
\hline
\end{tabular}

TABELA 3

Valores da produção primária líquida do fitoplâncton $<\mathbf{5 0} \mu$, produção secundária e da assimilação do mesozooplâncton da represa da Pampulha.

\begin{tabular}{|c|c|c|c|c|c|}
\hline Data & $\begin{array}{c}\text { Produção } \\
\text { prim. líquida } \\
\text { mgC.m-' }{ }^{-2} \cdot d^{-1}\end{array}$ & $\begin{array}{c}\text { Biomassa } \\
\text { zooplâncton } \\
\text { mgPS.m² }\end{array}$ & $\begin{array}{c}\text { Respiração } \\
\text { zooplâncton } \\
\text { mgC.m-2 } \mathbf{d}^{-1}\end{array}$ & $\begin{array}{l}\text { Produção } \\
\text { secundária } \\
\text { mgC.m } \mathbf{m}^{-2} \mathbf{d}^{-1}\end{array}$ & $\begin{array}{c}\text { Assimilação } \\
\text { zooplâncton } \\
\text { mgC.m-2 } \mathbf{d}^{-1}\end{array}$ \\
\hline Fevereiro & 185,9 & 1154,00 & 180,00 & 80,88 & 260,88 \\
\hline Abril & 13,45 & 1214,00 & 141,84 & 66,75 & 208,59 \\
\hline Agosto & 206,24 & 3082,00 & 325,44 & 160,29 & 485,73 \\
\hline Novembro & 79,82 & 1773,00 & 293,60 & 55,31 & 348,91 \\
\hline Valor anual ${ }^{*}$ & $37736,4^{*}$ & - & - & $34598,4^{*}$ & $119539,7^{*}$ \\
\hline
\end{tabular}

* Valor anual obtido pelo somatório dos doze meses do ano.

se aos valores verificados por Matsumura-Tundisi et al. (1981) e Tundisi et al. (1985), obtidos para o fitoplâncton total de diversos reservatórios do Estado de São Paulo e em lagos do médio Rio Doce.

As menores concentrações de clorofila-a foram observadas no período de janeiro-junho e os valores mais elevados foram obtidos no decorrer da estação seca, entre julho-outubro. No primeiro período, a reduzida disponibilidade de luz na coluna d'água, causada pela elevada turbidez inorgânica, observada durante as coletas, provavelmente limitou o desenvolvimento da biomassa fitoplanctônica. Já no segundo, ocorreu intenso "bloom" de Cyanobacteria (Microcystis spp.). Neste período, prevaleceram as condições ambientais favoráveis para o grande florescimento dessas algas, tais como maior concentração de nutrientes $(\mathrm{N}$ e $\mathrm{P})$, pouco vento e intensa radiação solar (Pinto-Coelho et al., 1997a).

Além disso, as colônias de Microcystis possuem um mecanismo que permite a flutuação junto à superfície, deste modo diminuindo a influência da limitação por luz (Paerl \& Ustach, 1982). Suas colônias geralmente foram maiores que $50 \mu \mathrm{m}$.

O carbono orgânico particulado (COP) da fração $<50 \mu$ m pode ser considerado alto $(2,35$ $\pm 0,22 \mathrm{mgC} . \mathrm{L}^{-1}$ ou $\left.13,6 \pm 2,4 \mathrm{gC} . \mathrm{m}^{-2}\right)$. No lago de Constance, na Alemanha, o COP anual médio da fração $<50 \mu \mathrm{m}$ foi inferior a $0,8 \mathrm{mgC} \cdot \mathrm{L}^{-1}$ (Pinto-Coelho, 1991). No lago Tupé, na Amazônia, Rai (1978) registrou COP anual médio de 4,43 $\mathrm{mgC} . \mathrm{L}^{-1}$ e nos reservatórios do médio Tietê, em São Paulo, o teor de carbono do séston total oscilou entre 4,0 e 6,0 mgC.m ${ }^{-2}$ (Tundisi et al., 1991).

Grande proporção do COP na represa durante o ano de 1994 foi composta por detritos e por heterotróficos planctônicos, tais como bactérias e protozoários. Somente uma pequena fração pode ser atribuída às algas (Fig. 4). Num ambiente onde é grande o aporte de esgotos domésticos e industriais, tal como a represa da Pampulha, é esperada a presença de grande quantidade de agregados formados por matéria orgânica, bactérias, protozoários e mesmo agregados de sedimentos com matéria orgânica adsorvida. Adicionalmente, a contribuição da fração não pigmentada do carbono sestônico aumentou ainda 
mais em 1995 no reservatório, período caracterizado por crescente eutrofização (Torres et al. 1998).

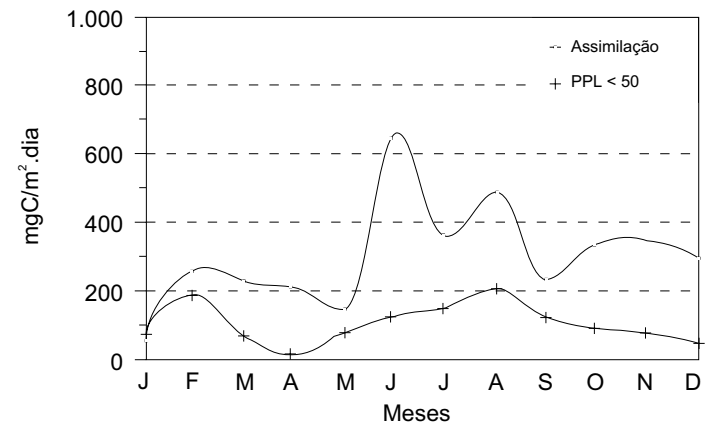

Fig. 5 - Comparação entre a taxa de produção primária líquida do fitoplâncton $<50 \mu \mathrm{m}$ e a taxa de assimilação do mesozooplâncton da Represa da Pampulha durante 1994. Valores obtidos a partir de interpolação não-linear (algoritmo de Bezier) das estimativas de produção primária e assimilação do zooplâncton. Data das coletas previamente convertidas em escala juliana.

A produção primária bruta (PPB) e líquida (PPL) do fitoplâncton $<50 \mu \mathrm{m}$, da Represa da Pampulha pode ser considerada de baixa a moderada durante o ano de 1994. Além disto, houve uma variação sazonal nos valores de produção primária desta fração do fitoplâncton, com um máximo anual sendo observado durante a estação seca, em agosto (Tabela 1). A baixa produção primária da represa da Pampulha, principalmente no período chuvoso do ano (janeiro-maio e novembro-dezembro), deve-se provavelmente à limitação por luz causada pela alta turbidez inorgânica e não à limitação causada por nutrientes.

Durante o pico da estação chuvosa, Calijuri (1988) registrou diminuição de mais de $80 \%$ na produção do fitoplâncton no reservatório de Barra Bonita, em São Paulo, devido ao material inorgânico em suspensão. Gianesella-Galvão (1985) demonstrou que a turbidez é um dos fatores limitantes da produção primária, principalmente no inverno, em alguns reservatórios de São Paulo.

Huszar (1994) constatou que, nas estações de coletas do Lago Batata impactadas por rejeitos da mineração de bauxita (argilas), o número, o biovolume e a densidade das espécies de fitoplâncton foram muito baixos. Ela atribuiu este comportamento à constante suspensão das argilas devido à ação do vento, provocando a sedimentação das algas juntamente com essas partículas de argila e também aos baixos valores de transparência. Silva (1995) detectou no lago Batata menor produção primária nas estações impactadas pelo rejeito de bauxita.

No lago Chapala, no México, Lind et al. (1992) mostraram que a produção primária anual foi muito baixa, sendo controlada pela turbidez inorgânica. Grobbelaar (1992) descreveu situação semelhante em um reservatório na África do Sul.

A taxa média de respiração, obtida neste trabalho para o mesozooplâncton da represa da Pampulha $\left(11,3 \mu \mathrm{IO}_{2} \cdot \mathrm{mgPS}^{-1} \cdot \mathrm{h}^{-1}\right)$, encontra-se dentro da faixa de valores descritos na literatura (LaRow et al., 1975; Raymont, 1983; Lampert, 1984 ).

Alguns estudos já demonstraram a existência de ritmos sazonais na taxa de respiração do zooplâncton. Cremer \& Duncan (1969), por exemplo, observaram variações sazonais nas taxas de respiração do zooplâncton em reservatórios britânicos. Os resultados deste estudo não permitiram evidenciar claramente a existência de variação sazonal nestas taxas. As diferenças, estatisticamente observadas nas taxas de respiração, podem também ter sido causadas pela interferência das condições experimentais, principalmente em relação à quantidade de biomassa de zooplâncton nos frascos experimentais. Em alguns experimentos, foram colocados valores mais elevados de biomassa do zooplâncton. Isto possivelmente levou à obtenção de baixos valores de TR que normalmente ocorrem sob tais condições experimentais (Pinto-Coelho et al., 1997b). A determinação experimental das taxas de respiração do zooplâncton pode ser influenciada por diversos fatores, tais como a quantidade de biomassa presente nas unidades experimentais, a temperatura e demais condições fisiológicas dos organismos (Duncan et al., 1970).

As taxas de produção secundária e de assimilação do mesozooplâncton da Represa da Pampulha foram moderadas durante o ano de 1994 (assimilação: 71-656 mgC.m. $\mathrm{m}^{-2} \cdot \mathrm{a}^{-1}$; produção secundária: 22-212 mgC.m $\mathrm{m}^{-2} \cdot \mathrm{d}^{-1}$ ou $\left.34,6 \mathrm{gC} \cdot \mathrm{m}^{-2} \cdot \mathrm{a}^{-1}\right)$. A produção secundária está na mesma faixa de valores registrada em alguns reservatórios da África do Sul (Robarts et. al, 1992). Haberman (1993) relatou produção secundária de 4,8 a 280,0 mgC. $\mathrm{m}^{-2} \cdot \mathrm{d}^{-1}$ no lago Yaskhan, na Turkmênia.

A taxa de assimilação do mesozooplâncton foi maior durante o período seco do ano, notadamente nos meses de junho-agosto. Estes maiores 
valores de assimilação são explicados pela maior biomassa presente nesta época (Tabela 3). A taxa de assimilação do mesozooplâncton esteve acima da produção primária líquida da fração do fitoplâncton $<50 \mu \mathrm{m}$ durante todos os meses do ano, à exceção de janeiro. Esta observação indica que o mesozooplâncton da represa da Pampulha depende, em grande parte, dos detritos e dos heterótroficos planctônicos (bactérias e protozoários) para sua sobrevivência e reprodução.

Outro aspecto que reforça a hipótese acima refere-se aos teores de lipídeos existentes no zooplâncton da represa da Pampulha. Um estudo recente demonstrou que estes teores foram bem mais baixos do que os detectados para este grupo de organismos em lagos temperados e oceanos frios (Pinto-Coelho et al., 1997). Uma explicação para isso seria o fato de o zooplâncton na Represa da Pampulha depender de recursos alimentares com baixo valor nutricional, como os detritos.

Diversos autores têm demonstrado que o zooplâncton pode se alimentar basicamente de detritos e heterotróficos, deixando a "cadeia clássica" de pastoreio para um segundo plano. Darnell (1961) demonstrou que o zooplâncton do lago Pontchartrain, na Lousiana, EUA, alimentava-se, basicamente, da matéria orgânica rica em bactérias. Imevbore (1967), estudando o reservatório de Ibadan, na Nigéria, observou que o "pico" nas populações do zooplâncton era precedido por um pico no material particulado na água. Esse autor concluiu que o zooplâncton alimentava-se diretamente dos detritos ricos em bactérias, sendo pouco o alimento fornecido pelo fitoplâncton.

Arruda et al. (1983), estudando uma represa no rio Big Blue, Kansas, EUA, sugeriu que a matéria orgânica adsorvida em partículas de sedimento em suspensão (argilas) poderia constituir uma importante fonte de nutrição para o zooplâncton filtrador.

Como mencionado anteriormente, a Represa da Pampulha recebe uma grande carga de esgotos domésticos sem qualquer tipo de tratamento, o que representa enorme aporte alóctone de matéria orgânica. Esta matéria orgânica pode constituir importante recurso alimentar para zooplâncton filtrador de três formas: 1) formação de agregados de matéria orgânica ricos em bactérias; 2) adsorção da matéria orgânica em partículas inorgânicas em suspensão (argilas principalmente), com possível presença de bactérias e protozoários; 3) substrato para bactérias de vida livre na coluna d'água. Estas bactérias poderiam ser utilizadas diretamente pelos grandes filtradores, como Daphnia sp. (Peterson \& Hobbie, 1978; Porter et al., 1985) ou indiretamente através da cadeia microbiana ou "microbial loop" (Azam et al., 1983; Stockner \& Porter, 1988; Wylie \& Currie, 1991; Markosová \& Jezek, 1993).

\section{CONCLUSÕES}

a) A maior contribuição ao carbono sestônico na Represa da Pampulha foi devida a fontes não pigmentadas, oriundas de microheterótrofos planctônicos e "detritos".

b) Embora seja eutrófica, a Represa da Pampulha apresentou valores de produção primária baixos a moderados nas duas frações consideradas, o "fitoplâncton de rede" $(50-160 \mu \mathrm{m})$ e o nanoplâncton $(<50 \mu \mathrm{m})$.

c) A assimilação do zooplâncton, estimada a partir do método de Winberg, indica claramente que a cadeia microbiana ou de detritos deve ser a principal via alimentar do zooplâncton no reservatório da Pampulha.

Agradecimentos - Os autores agradecem à Fundação de Amparo à Pesquisa do Estado de Minas Gerais, FAPEMIG (Proc CBS 152/92), pela concessão de auxílio à pesquisa, e à Fundação CAPES, pela concessão da bolsa de mestrado a Marcos A. Araújo dentro do programa de Ecologia, Conservação e Manejo da Vida Silvestre ECMVS/UFMG. Expressamos também os nossos agradecimentos à Prefeitura Municipal de Belo Horizonte, $\mathrm{PBH}$, que financiou parcialmente esta pesquisa através do convênio SMMA/FUNDEP(UFMG).

\section{REFERÊNCIAS BIBLIOGRÁFICAS}

APHA, 1992, Standard methods for examination of water and wastewater. 18 a edition, American Public Health Association, Washington, pp. 5.1-5.15.

ARCIFA, M. S., 1984, Zooplankton composition of ten reservoirs in Southern Brazil. Hydrobiologia, 113: 137-145.

ARRUDA, J. A., MARZOLF, G. R. \& FAULK, R. T., 1983, The role of suspended sediments in the nutrition zooplankton in turbid reservoirs. Ecology, 64: 1225-1235.

AZAM, F., FENCHE1, T., FIELD, J. G., GRAY, J. S., MEYER-REIL, L. A. \& THINGSTAD, F., 1983, The ecological role of Water-column microbes in the sea. Mar. Ecol. Prog. Ser, 10: 257-263.

BERBEROVIC, R. \& PINTO-COELHO, R. M., 1989, Dry first, measure later: a new procedure to preserve and measure zooplankton for ecophysiological studies. J. Plankton Res., 11(5): 1109-1116. 
CALIJURI, M. C., 1988, Respostas fisioecológicas da comunidade fitoplanctônica e fatores ecológicos em ecossistemas com diferentes estágios de eutrofização. Tese de Doutorado, UFSCar, São Carlos, 293p.

CHAMPS, J. R. B., 1991, O problema de assoreamento da Represa da Pampulha e as medidas adotadas para seu controle. I Encontro Nac. de Eng. de Sedimentos, pp. 93-96.

CHAMPS, J. R. B., 1992, Algumas considerações sobre a situação sanitária da Bacia da Pampulha. Anais do Seminário Bacia Hidrográfica da Pampulha, pp. 134-142.

CISSEROS, R. O. \& MANGAS, E. I., 1991, Zooplankton studies in tropical lake Lake Xolotlán, Nicaragua. Verh. Internat. Verein. Limnol., 24: 1167-1170.

CREMER, G. A. \& DUNCAN, A., 1969, A seazonal study of zooplanktonic respiration under field conditions. Verh. Internat. Verein. Limnol., 17: 181-190.

DARNELL, R. M., 1961, Trophic spectrum of an estuarine community based on studies of lake Pontchartrain, Louisiana. Ecology, 42: 553-568.

DUNCAN, A., CREMER, G. A. \& ANDREW, T., 1970, The measurement of respiratory rates under field and laboratory conditions during an ecological study on zooplankton. Pol. Arch. Hydrobiologia, 17: 149-160.

ERIKSON, R.; HOOKER, E. \& MEJIA, M., 1991, The dynamics of photosynthetic activity in Lake Xolotlán, Nicaragua. Verh. Internat. Verein. Limnol., 24: 1163-1166.

FENCHEL, T., 1988, Marine plankton food chains. Ann. Rev. Ecol. Syst., 19: 19-38.

GIANESELLA-GALVÃO, S. M. F., 1985, Primary production in ten reservoirs in Southern Brazil. Hydrobiologia, 122: $81-88$.

GIANI, A., PINTO-COELHO, R. M., OLIVEIRA, S. J .M \& PELLI, A., 1988, Ciclo sazonal de parâmetros físicoquímicos da água e distribuição horizontal de nitrogênio e fósforo no Reservatório da Pampulha, Belo Horizonte, MG, Brasil. Ci. e Cult., 40: 69-77.

GROBBELAAR, J. U., 1992, Nutrients versus physical factors in determining the primary productivity of waters with high inorganic turbidity. Hydrobiologia, 238: 177-182.

HABERMAN, J., 1993, Zooplankton of Lake Yaskhan. Biological abstracts, 1994.

HUSZAR, V. L. M., 1994, Fitoplâncton de um lago amazônico impactado por rejeito de bauxita, Lago Batata, Pará, Brasil: estrutura da comunidade, flutuações espaciais e temporais. Tese de Doutorado, UFSCar, São Carlos, SP, 328p.

IMEVBORE, A. M., 1967, Hydrology and plankton of Eleiyele Reservoir Ibadan, Nigeria. Hydrobiologia, 30: 154-176.

LAMPERT, W., 1984, The measurement of respiration. In: Downing \& Rigler A Manual on Methods for Assessment of Secondary Productivity in Freshwater (eds.), Blackwell Scientific Publications, London, pp. 413-468.

LaROW, E. J., WILKINSON, J. W. \& KUMAR, K. D., 1975, The effect of food concentration and temperature on respiration and excretion in herbivorous zooplankton. Verh. Internat. Verein. Limnol., 19: 966-973.
LIND, O. T., DOYLE, R., VODOPICH, D. S. \& TROTTER, B. G., 1992, Clay turbidity: Regulation of phytoplankton production in a large, nutrient-rich tropical lake. Limnol. Oceanogr., 37: 549-565.

LORENZEN, C. J., 1967, Determination of clorophyll an pheopigments: spectrophotometric equations. Limnol. Oceanogr., 12: 343-346.

MARKOSOVÁ, R. \& JEZEK, J., 1993, Bacterioplankton interactions with Daphnia in experimental enclosures. Hydrobiologia, 264: 85-99.

MATSUMURA-TUNDISI, T., HINO, K. \& CLARO, S. M., 1981, Limnological studies at 23 reservoirs in southern Brazil. Verh. Internat. Verein. Limnol., 21: 1040-1047.

PAERL, H. \& USTACH, J. F., 1982, Blue green algal scums: an explanation for their occurrence during freshwater blooms. Limnol. Oceanogr., 27: 212-217.

PETERSON, B. J. \& HOBBIE, J. E., 1978, Daphnia grazing on natural bacteria. Limnol. Oceanogr., 23: 1039-1044.

PINTO-COELHO, R. M., 1991, Zooplankton grazing in Lake Constance: In situ measurements of temporal variations, contributions of size fractions, regulatory factors of specific filtering rates and potential impact as loss factor of phytoplankton production. Diss. Doc. rer. nat., Universität Konstanz, Alemanha, 200p.

PINTO-COELHO, R. M., GIANI, A., TORRES, I. C. \& FIGUEIREDO, C. C., 1997a, Biomonitoramento plurianual de variáveis limnológicas no Reservatório da Pampulha. Relatório Final. Convênio Secretaria Municipal do Meio Ambiente-PBH/Fundação de Desenvolvimento da Pesquisa -FUNDEP., 87p.

PINTO-COELHO, R. M., MOURA, R. T. \& MOREIRA, A., 1997b, Zooplankton and bacteria contribution to phosphorus and nitrogen internal cycling in a tropical and eutrophic reservoir: Pampulha Lake, Brazil. Int. Revue Ges. Hydrobiol., 82: 185-200.

PINTO-COELHO, R. M., AMORIM, M. K. \& DA COSTA, A. R., 1997, Temporal dynamics of lipids in the zooplankton of two tropical reservoirs of different trophic status. Verh. Internat. Verein. Limnol. 26: 584-587.

POMEROY, L. R., 1974, The oceans food web, a changing paradigm. BioScience, 24: 499-504.

POMEROY, L. R., WIEBE, W. J., 1988, Energetics of microbial food webs. Hydrobiologia, 159: 7-18.

POMEROY, R. \& KIRSCHMANN, H. P., 1945, Determination of dissolved oxygen. Proposed modification of Winkler Method. Industrial Engeneering Chemistry Anaytical Edition, 17: 715-716.

PORTER, K. G., SHERR, E. B., SHERR, B. F., Pace, M. \& Sanders, R. W., 1985, Protozoa in planktonic food webs. J. Protozool., 32: 159-170.

POURRIOT, R. \& CHAMP, H., 1982, Consommateurs et production secondaire. In: Écologie du plancton des eaux continentales, R. Pourriot, J. Capblancq, P. Champ \& J.A. Meyer Masson (eds.), Paris, 195p.

RAI, H., 1978, Distribution of carbon, chlorophyll-a and phaeo-pigments in the black water lake ecosysytem of Central Amazon Region. Arch. Hydrobiol., 82: 74-87. 
RAYMONT, J. E. G., 1983, Plankton and productivity in the oceans - Zooplankton. 2o vol, 2aㅡ., edergamon Press, New York.

ROBARTS, R. D., ZOHARY, T., JARVIS, A. C. \& PAIS-MADEIRA, C. M., 1992, Phytoplankton and zooplankton population dynamics and production of a recent formed African reservoir. Hydrobiologia, 237: 47-60.

SCHMIDT, G. W., 1973, Primary production of phytoplankton in a tropical flood-plain lake Central Amazonia, Lago Castanho, Amazonas, Brazil. Amazoniana, 4: 379-404.

SENDACZ, S., 1984, A study of the zooplankton community of Billings Reservoir, São Paulo. Hydrobiologia, 113: 121-127.

SILVA, F. R. F., 1995, Produção primária fitoplanctônica em um lago amazônico impactado por bauxita, Lago Batata, Pará. Tese de Doutorado, UFSCar, São Carlos. $117 \mathrm{p}$.

SIMON, M. \& TILZER, M. M., 1987, Bacterial response to seazonal changes in primary production and phytoplankton biomass in Lake Constance. J. Plankton Res., 9: 535552.

SNEDECOR, G. W. \& COCHRAN, W. G., 1989, Statistical Methods. 8 a ed., Iowa State University, Press/AMES, $503 \mathrm{p}$.

SOKAL, R. R. \& ROHLF, F. J., 1981, Biometry, 2a ed., Freeman and Company, San Francisco. 859p.

STOCKNER, J. G. \& PORTER, K. G., 1988, Microbial food webs in freshwater planktonic ecosystems. In: S. R. Carpenter (ed.), Complex interactions in lake communities, Springer, pp. 69-83.

STRIKLAND, J. D. H., 1960, Measuring the production of marine phytoplankton. Fish. Res. Bd. Canada Bull. 122: 172.

TALLING, J. F., WOOD, R. B., PROSSER, M. V. \& BAXTER, R. M., 1973, The upper limit of photosynthetic productivity by phytoplankton: evidence from Ethiopian soda Lakes. Freshwat. Biol., 3: 53-76.

TORRES, I. C., ARAÚJO, M. R. \& PINTO-COELHO, R. M., 1998, Variação temporal de carbono pigmentado, carbono orgânico dissolvido e particulado na Represa da Pampulha, Belo Horizonte, MG. Rev. Bras. Biol., 58(1): 131-141.
TUNDISI, J. G., MATSUMURA-TUNDISI, T., CALIJURI, M. C. \& NOVO, E. M. L., 1991, Comparative limnology of five reservoirs in the middle Tietê River, São Paulo State. Verh. Internat. Verein. Limnol., 24: 1489-1496.

TUNDISI, J. G., SAIJO, Y., HENRY, R. \& NAKAMOTO, N., 1985, Primary productivity, phytoplankton biomass and light photosynthesis responses of four lakes in the Rio Doce Lake System. In: Y. Saijo, \& J. G. Tundisi, [eds.], Limnological studies in Rio Doce Valley Lakes and Pantanal Wetland, Brazil. 2nd. Report. Nagoya, Japan, pp. 21-49.

VOLLENWEIDER, R. A., 1974, A Manual on Methods for Measuring Primary Production in Aquatic Environments. 2nd ed. IBP Handbook no12, Blackwell Scientific Publications, London, 224p.

WEISSE, T., 1990, Trophic interactions among heterotrophic microplankton, nanoplankton, and bacteria in lake Constance. Hydrobiologia, 191: 111-122.

WEISSE, T., 1994, Structure of microbial food webs in relation to the trophic status of lakes and fish grazing pressure: a key role of cyanobacteria? In: R. M., PintoCoelho, A. Giani \& E. Von Sperling, Ecology and human impact on lakes and reservoirs in Minas Gerais with special reference to future development and management strategies (eds.), Belo Horizonte, pp. 55-70.

WILLIAMS, P. J. B \& ROBERTSON, J. E., 1991, Overall planktonic oxygen and carbon dioxide metabolisms: the problem of reconciling observations and calculations of photosynthetic quotients. J. Plankton Res., 13: 153-169.

WINKLER, 1888, Die Bestimmung des in Wasser gelosten Sauerstoffes. Berichte der Deutschen Chemischem Gesellschaft, 21: 2843-2854.

WYLIE, J. L. \& CURRIE, D. J., 1991, The relative importance of bacteria and algae as food sources for crustacean zooplankton. Limnol. Oceanogr., 36: 708-728. 